\title{
Trace element Analyses in a Black South African Pregnant Population: The role of Dietary history and Antenatal supplements in the occurrence of pre-eclampsia
}

\author{
D A Ofusori ${ }^{1,2 *}$, J Moodley $^{3}$, R Moodley ${ }^{4}$, T Padayachi $^{5}$ and T Naicker ${ }^{1}$ \\ ${ }^{1}$ Optics and Imaging Centre, School of Laboratory Medicine \& Medical Sciences, University of KwaZulu-Natal, Durban, South Africa \\ ${ }^{2}$ Department of Anatomy and Cell Biology, Faculty of Basic Medical Sciences, Obafemi Awolowo University, Ile-Ife, Osun State, Nigeria \\ ${ }^{3}$ Department of Women Health, College of Health Sciences, University of KwaZulu-Natal, Durban, South Africa \\ ${ }^{4}$ Department of Chemistry, School of Chemistry and Physics, University of KwaZulu-Natal, Durban, South Africa \\ ${ }^{5}$ Lancet Laboratories, Chemical Pathology Division, Durban, South Africa
}

\begin{abstract}
Background: The aim of this study was to establish the role of dietary history and antenatal supplementation of Black South African pregnant women in relation to serum trace elements and related hormones (calcium [Ca], magnesium [Mg], iron [Fe], vitamin D, phosphates, parathyroid hormone [PTH] and albumin $[\mathrm{ALB}]$ ) in the occurrence of pre-eclampsia $(\mathrm{PE})$.

Methods: Women matched for maternal age were recruited; [normotensive, early onset and late onset PE]. Patient demographics and a dietary history, which included calcium enriched foods and those that inhibit absorption of calcium were recorded in a structured data sheet. Serum levels of Ca, phosphate, Fe, Mg, albumin ALB, Vitamin D and plasma levels of PTH were assayed by standard laboratory procedures.

Results: Serum levels of $\mathrm{Ca}$, phosphate, $\mathrm{Mg}$, PTH and Fe were within the normal range in all three groups. Serum albumin and vitamin D levels were below the normal reference range, while the serum PTH and ALB levels were significantly different ( $\mathrm{p}=0.0001)$ across all groups. The dietary history was similar across the groups.
\end{abstract}

Conclusion: Thus, the present study confirms that serum levels of calcium, phosphate, $\mathrm{Mg}, \mathrm{Fe}$ and plasma level of PTH are within the normal reference range in a Black South African population and that the dietary history and antenatal supplementation during pregnancy played an important role in the occurrence PE.

\section{Introduction}

Preeclampsia (PE) is a leading cause of life-threatening maternal morbidity and mortality world-wide and especially in South African [1]. Despite extensive research, the exact cause of PE remains elusive. Thus, treatment is empirical and involves the identification of patients with early clinical signs of PE, lowering of high blood pressure and timely delivery [2]. Recently, epidemiological studies have suggested that diets containing inadequate levels of folic acid, $n 3$ polyunsaturated fatty acids and vitamin $\mathrm{D}$ at conception are associated with low birth weight babies and intrauterine growth restriction, and possibly have role in the etiology of PE [3]. Furthermore, some reports suggest that in low-middle income countries (LMIC), which have calcium deficient diets, rates of PE are high [4]. It is therefore plausible that dietary deficiencies of essential elements such as calcium (Ca) and vitamin D may have roles in the pathogenesis of PE [3]. This is especially true when there is evidence of a metabolic interplay between $\mathrm{Ca}$, magnesium $(\mathrm{Mg})$, vitamin $\mathrm{D}$, phosphate and parathyroid hormone $(\mathrm{PTH})$ in the absorption of trace elements and the synthesis of vasoactive substances such as prostacyclin and nitric oxide [5-7]. In addition, both prostacyclin and nitric oxide are implicated in the pathogenesis of PE [5-7].

It has been reported that a Ca deficient diet leads to an increased intracellular ionized calcium concentration during pregnancy and that the ionized fraction is crucial for the synthesis of vasoactive substances in the endothelium $[5,6]$. Studies have also shown impaired $\mathrm{Ca}^{2+}$ metabolism in pre-eclamptic syncytiotrophoblast stemming from hypoxic stress, which in turn induces expression of $\mathrm{Ca}^{2+}$ transport proteins in the placenta to maintain the balance between maternal and fetal $\mathrm{Ca}^{2+}$ [6]. In addition, vitamin $\mathrm{D}$ a group of fat-soluble steroids is responsible for intestinal absorption of $\mathrm{Ca}$ and phosphate and thus may be implicated in $\mathrm{Ca}$ deficiency and warrant investigation. There is a paucity of information on the correlation of the dietary history, antenatal supplementation and trace elements in a Black South African pregnant population. Thus, this study was designed to compare the serum levels of trace elements $(\mathrm{Ca}, \mathrm{Mg}, \mathrm{Fe})$, vitamin $\mathrm{D}$, phosphate, albumin and PTH levels with the dietary history and antenatal supplementation of Black South African women with preeclampsia and a control pregnant normotensive group.

Correspondence to: David A Ofusori, Department of Anatomy \& Cell Biology, Faculty of Basic Medical Sciences, Obafemi Awolowo University Ile-Ife, Osun State, Nigeria, Tel: 234-803-445-5715, E-mail: davidofus234@yahoo.com

Key words: Normotensive, Pre-eclampsia, dietary history, antenatal supplementation

Received: March 09, 2018; Accepted: March 19, 2018; Published: March 23 , 2018 


\section{Materials and Methods}

This study was approved by the institutional Biomedical Research Ethics Committee (BE388/13). Following written informed consent, participants from a regional hospital were recruited between 2014 and 2015. Recruitment was done randomly using their medical records (50 normotensive, 50 early onset (EOPE: $\leq 33$ weeks gestational age) and 50, late onset pre-eclampsia (LOPE: > 34 weeks gestational age). Preeclampsia was defined in accordance with the National High Blood Pressure Education Program as high blood pressure $(\geq 140 / 90 \mathrm{~mm}$ $\mathrm{Hg}$ before 20 weeks of gestation for EOPE and $\geq 140 / 90 \mathrm{~mm} \mathrm{Hg}$ after 20 weeks for LOPE) and proteinuria ( $\geq 300 \mathrm{mg} / 24$ hours) [8]. Patient demographics and other relevant information (ethnicity, maternal age, gestational age, blood pressure levels, maternal weight, height and dietary profile details) were collected on a structured data form.

Approximately $5 \mathrm{mls}$ of venous blood was obtained from each patient without application of a tourniquet and transferred into appropriate tubes. All blood samples were spun at $3000 \mathrm{rpm}$ on an eppendorf centrifuge (centrifuge $5804 \mathrm{R}$ ) for $10 \mathrm{~min}$ at $4^{\circ} \mathrm{C}$. The supernatant (serum and plasma) were transferred into cryotubes and the samples were stored at $-80^{\circ} \mathrm{C}$ until analysis.

Biochemical parameters (Ca, Mg, Fe, vitamin D, ALB, phosphate and $\mathrm{PTH}$ ) were determined as follows: the serum and plasma samples were transferred on dry ice to the laboratories. All samples were allowed to thaw at room temperature for 3 hours before testing. Samples were checked for fibrin or gel clots using an applicator stick. The serum samples were processed for $\mathrm{Ca}, \mathrm{ALB}, \mathrm{Mg}$, Fe, phosphate and vitamin D while the plasma samples were tested for PTH. All the tests were performed using standard methods recommended by the manufacturer and when applicable, samples were retested for accuracy.

\section{Instruments and Kits used}

\section{Instruments}

The Abbott Architect ci 8200 were used for serum analyses of calcium, albumin, magnesium, phosphate and iron; the Abbott Architect i2000 SR for serum analysis of $25 \mathrm{OH}$ Vitamin D and the Cobas e411 for plasma analysis of PTH.

\section{Kits}

Albumin (ALBUMIN BCP, Abbott Laboratories Inc., USA); Calcium (ARSENAZO III, Abbott Laboratories Inc., USA); Magnesium enzymatic (Abbott Laboratories Inc., USA); Phosphate (PHOSPHOMOLYBDATE, Abbott Laboratories Inc., USA); Iron (FERENE, Abbott Laboratories Inc., USA); 25OH Vitamin D (CMIA, Abbott Laboratories Inc., Germany) and PTH (ECLIA, Roche, Germany).

\section{Statistical Analysis}

Data were analyzed using IBM SPSS Statistics 22. Normotensive, EOPE and LOPE groups were analyzed by chi-square test or Fisher's exact test for categorical variables. ANOVA was used for normally distributed numerical variables and Kruskal Wallis test for nonnormally distributed numerical variables. In addition, the Duncan multiple range test option was used to compare the groups. A p value of $<0.05$ was considered statistically significant

\section{Results}

Table 1 shows that the maternal age, gestational age, systolic and diastolic blood pressures were significantly different across the normotensive, EOPE and LOPE groups. There was no significant difference in the Body Mass Index (BMI) across all groups. The blood pressure levels were significantly higher in the PE compared with the normotensive group $(\mathrm{p}=0.000)$.

Table 2 shows a similar dietary pattern in all three groups with the exception of coffee consumption which was slightly higher in the normotensive group compared to the PE group.

\section{Antenatal Prophylactic Supplements}

Approximately half of the participants received prophylactic folic acid, ferrous sulphate or ferrous fumarate supplements, while over $50 \%$ had Ca supplementation (1-1.5 grams daily) across all the groups (Table 3).

\section{Serum Trace Element Assay Results (Table 4) \\ Calcium (T) and Adjusted Calcium (Adj) Levels}

The serum levels of $\mathrm{T}$ and Adj calcium were within normal range and were significant (at $\mathrm{p}=0.05$ for $\mathrm{T}$ and Ad calcium) across the three groups.

\section{Serum Phosphate Levels}

Serum phosphate level were within normal range across the three groups with no significant difference when compared ( $\mathrm{p}=0.05)$.

\section{Serum Parathyroid hormone (PTH) and Albumin (ALB) Levels}

The serum PTH and ALB levels was significantly different $(\mathrm{p}=0.05)$ when early and late onset PE groups were compared with the normotensive group. However, there was no significant difference in PTH and ALB levels when early and late onset PE groups were compared.

\section{Magnesium (Mg) and Iron (Fe)}

The Mg and Fe levels were within normal reference values. The Mg level was significant across the three groups whereas the Fe level was not significant when compared across the three groups.

\section{Vitamin D}

The vitamin D levels were low but not significantly different across all three groups $(\mathrm{p}=0.05)$.

\section{Discussion}

Maintenance of a trace element rich diet has been reported to reduce the incidence of PE [9-11]. In the present study the dietary history of Black South African pregnant women was correlated with measured trace elements and the hormonal status to determine if their diet had a role to play in the occurrence of $\mathrm{PE}$. The results showed that serum levels of $\mathrm{Ca}$, phosphate, $\mathrm{Mg}$ and $\mathrm{Fe}$ were within the normal range in the three groups. This observation was expected because $\mathrm{Ca}$ and $\mathrm{Mg}$ levels are known to be reduced in pregnancy due to both maternal dietary deficiency and the need for fetal bone mineralization [9]. A previous study also reported a reduction in serum levels of Ca and Mg in PE [3]. The reason for the relative normalcy of these measured parameters in the present study however may be explained by the fact that over $50 \%$ of the study participants had received Ca supplementation (Table 3). Also, a study from South Africa which investigated chronic Ca status by measuring maternal hair found no differences between pregnant 
Ofusori DA (2018) Trace element Analyses in a Black South African Pregnant Population: The role of Dietary history and Antenatal supplements in the occurrence of pre-eclampsia

Table 1. General clinical characteristics of all study participants $(n=150)$

\begin{tabular}{|c|c|c|c|c|}
\hline Parameter & Normotensive & Early Onset pre-eclampsia & Late Onset pre-eclampsia & p value \\
\hline Maternal age (yrs) & $23.38 \pm 4.878$ & $26.71 \pm 6.37$ & $24.82 \pm 6.69$ \\
\hline Gestational Age (wks) & $35.85 \pm 4.628$ & $30.64 \pm 4.95$ & $36.79 \pm 1.65$ \\
\hline BMI & $33.72 \pm 32.69$ & $31.22 \pm 7.65$ & $29.70 \pm 6.77$ \\
\hline Systolic BP (mm/Hg) & $107.84 \pm 13.680$ & $159.30 \pm 14.01$ & $152.56 \pm 10.04$ \\
\hline Diastolic BP (mm/Hg) & $66.78 \pm 10.170$ & $104.11 \pm 11.21$ & 0.000 \\
\hline
\end{tabular}

Table 2. Dietary history of all participants

\begin{tabular}{|c|c|c|c|}
\hline Characteristics & Normotensive & Early Onset pre-eclampsia & Late Onset pre-eclampsia \\
\hline Coffee (\%) & 40 & 21.7 & 31.7 \\
\hline Ceylon Tea (\%) & 63.6 & 75.7 & 69.4 \\
\hline Rooibos Tea (\%) & 67.3 & 85.5 & 70 \\
\hline Milk Tea (\%) & 89.1 & 88.6 & 90.3 \\
\hline Cheese (\%) & 92.7 & 87.1 & 88.7 \\
\hline Yoghurt (\%) & 92.7 & 94.3 & 95.2 \\
\hline Green Vegetables (\%) & 81.8 & 91.4 & 88.7 \\
\hline Nuts (\%) & 25.5 & 15.7 & 22.5 \\
\hline Fruits (\%) & 100 & 97.1 & 95.2 \\
\hline Beans (\%) & 80 & 97.1 & 82.3 \\
\hline Bread (\%) & 96.4 & 97.1 & 98.4 \\
\hline Cereal (\%) & 81.8 & 85.7 & 77.4 \\
\hline Fish (\%) & 94.5 & 94.3 & 96.8 \\
\hline Meat (\%) & 100 & 100 & 100 \\
\hline
\end{tabular}

Table 3. Antenatal supplements administered to the patients

\begin{tabular}{|c|c|c|c|}
\hline Characteristics & Normotensive & Early Onset pre-eclampsia \\
\hline Folic Acid (\%) & 61.8 & 55.1 \\
\hline FeSO (\%) & 58.2 & 42.0 \\
\hline Calcium (\%) & 61.8 & 63.8 & 46.8 \\
\hline Ferrous fumarate (\%) & 46.3 & 43.5 & 73.5 \\
\hline Vitamin C (\%) & 11.3 & 5.8 & \\
\hline Multivitamins (\%) & 9.1 & 10.1 \\
\hline
\end{tabular}

Table 4. Trace elements and hormonal assay across the groups

\begin{tabular}{|c|c|c|c|c|}
\hline Measured Parameters & Normal Range & Normotensive & Early Onset pre-eclampsia & Late Onset pre-eclampsia \\
\hline $\mathrm{Ca}(\mathrm{T})(\mathrm{mmol} / \mathrm{L})$ & $2.10-2.55$ & $2.25 \pm 0.15^{\mathrm{b}}$ & $2.22 \pm 0.15^{\mathrm{ab}}$ & $2.18 \pm 0.11^{\mathrm{a}}$ \\
\hline $\mathrm{Ca}(\mathrm{Ad})(\mathrm{mmol} / \mathrm{L})$ & $2.10-2.55$ & $2.42 \pm 0.19^{\mathrm{a}}$ & $2.50 \pm 0.12^{\mathrm{b}}$ & $2.47 \pm 0.10^{\mathrm{ab}}$ \\
\hline PHOSPHATE (mmol/L) & $0.87-1.45$ & $1.24 \pm 0.27^{\mathrm{a}}$ & $1.26 \pm 0.22^{\mathrm{a}}$ & $1.24 \pm 0.15^{\mathrm{a}}$ \\
\hline PTH (pg/ml) & $15-65$ & $26.36 \pm 12.71^{\mathrm{a}}$ & $40.14 \pm 19.11^{b}$ & $43.72 \pm 19.64^{b}$ \\
\hline $\operatorname{ALB}(g / L)$ & $35-50$ & $31.55 \pm 5.31^{\mathrm{b}}$ & $26.02 \pm 3.58^{\mathrm{a}}$ & $25.38 \pm 3.42^{\mathrm{a}}$ \\
\hline VIT D (ng/mL) & $30-100$ & $23.07 \pm 9.42^{\mathrm{a}}$ & $20.78 \pm 8.66^{\mathrm{a}}$ & $21.46 \pm 8.75^{\mathrm{a}}$ \\
\hline $\mathrm{Mg}(\mathrm{mmol} / \mathrm{L})$ & $0.66-1.07$ & $0.74 \pm 0.06^{\mathrm{a}}$ & $0.77 \pm 0.12^{\mathrm{ab}}$ & $0.78 \pm 0.07^{\mathrm{b}}$ \\
\hline $\mathrm{Fe}(\mu \mathrm{mol} / \mathrm{L})$ & $9.0-30.4$ & $14.24 \pm 5.61^{\mathrm{a}}$ & $16.88 \pm 12.46^{\mathrm{a}}$ & $14.60 \pm 7.08^{\mathrm{a}}$ \\
\hline
\end{tabular}

Values are given as mean \pm SEM for Ca, Phosphate, PTH, ALB, Vit D, Mg, Iron. a, b, ab, within rows signifies that means with different letters differs significantly at $\mathrm{p}<0.05$ while means with the same letters does not differ significantly at $\mathrm{p}<0.05$ (using one-way ANOVA with Duncan multiple range test)

$T=$ total; ad = adjusted PTH = parathyroid $;$ alb = albumin $;$ Vit = vitamin $;$ mg = magnesium; FE = Iron

normotensive and PE groups [4]; these authors also did not find any differences between the control and the study groups with regards to serum $\mathrm{Ca}$ and $\mathrm{Mg}$ levels, and indicated that their findings did not support the current belief that $\mathrm{Ca}$ supplementation corrects a dietary deficiency and thereby reduces the risk of the development of PE [4]. The findings of the present study were similar to that of Richards et al., yet one cannot ignore the findings of randomized control trails and meta-analyzes which show a reduction in the incidence of PE when $\mathrm{Ca}$ supplementation is provided during pregnancy $[10,11]$. It is plausible that other metabolic interactions contribute to the responses of Ca supplementation. Therefore, the levels of ALB, vitamin $\mathrm{D}$, phosphate and PTH hormone were investigated because of their metabolic interplay. Serum Mg levels correlate very well with Ca levels and vitamin $\mathrm{D}$ levels assist in the absorption of $\mathrm{Ca}$ and low Ca levels increase PTH release leading to vasodilation. The present study did not find any differences in the levels of these trace elements and in serum PTH levels; the study did however find low serum levels of vitamin D and serum ALB. The low serum ALB levels might reflect poor nutrition across the groups. This may appear contradictory to the findings of our dietary survey in which it appears that all study participants consumed reasonable amounts of $\mathrm{Ca}$ rich food. The dietary survey however was a limitation of our study in that study participants were only asked the question whether $\mathrm{Ca}$ enriched foods were consumed regularly over a period of a month. Besides, over half of our participants were on $\mathrm{Ca}$ and Fe supplementation. Furthermore, the antenatal supplementation survey neither enquires into details of compliance nor the timing of consuming the $\mathrm{Ca}$ and $\mathrm{Fe}$ supplements. It is known that dietary iron decreases $\mathrm{Ca}$ absorption, therefore the clinical protocols at the study 
site indicate that a sufficient time interval (4 hours) is taken prior to consuming one or the other supplement.

The participants in the present study were also provided with multivitamin capsules. However, these contain minute amounts of vitamin D. Nonetheless, the dietary survey did not show major differences in vitamin $\mathrm{D}$ levels between the groups. Ceylon tea, rooibos tea, milk, tea, fish, meat, cereal, bread, vegetables, fruits, cheese and yogurt were observed to be some of the most consumed dietary products across the three groups. These diets have been reported to be an excellent source of $\mathrm{Ca}$, potassium, $\mathrm{Mn}, \mathrm{Fe}, \mathrm{Zn}$ and hydroxyl acid $[9,12]$. In fact, rooibos tea is known to contain aspalathin, a bioflavinoid that offers effective protection against the formation of free radicals in hypertension [13] and in relieving stress, however yogurt increases the absorption of calcium [14].

Less intake (below average) of coffee may have also played a significant role in the normalization of serum $\mathrm{Ca}$ level as observed in this study. The $\mathrm{Ca}(\mathrm{T})$ level in normotensive group was significantly reduced when compared with early onset and late onset pre-eclampsia groups. This might be traceable to the fact that higher percentage of normotensive group consumed more coffee that the other groups; Coffee inhibits the absorption of $\mathrm{Ca}$ [15]. Nuts were the least consumed of all diets in all the three groups, but both PE groups may have consumed more nuts compared to the normotensive group. Nuts are reported to be particularly rich in antioxidants, vitamins, minerals and omega-3 fatty acids ${ }^{7}$. Also, several studies have shown that regular nut consumption is associated with a reduced risk of medical conditions such as hypertension, endothelial dysfunction, coronary heart disease, inflammation and type 2 diabetes [16-17].

Parathyroid hormone is secreted in response to low serum calcium levels. The present study found that there was a significant difference in the plasma levels of PTH across the three groups (Table 4). The high PTH levels in the PE group compared to the normotensive group may perhaps occur in response to the initial low level of calcium which could have been normalized by calcium supplementation.

Vitamin D encourages the synthesis of proteins which facilitate the absorption of calcium. Serum vitamin D levels in the present study though within the normal limits were at the lower end of the reference range. The reason for this possible deficiency may be due to either low vitamin D supplementation or religious and cultural beliefs surrounding early morning sun exposure in pregnant women [3,7]. It is important to note that pregnant women with little exposure of their skin to sunlight are at a greater risk of vitamin D deficiency and may need additional vitamin D supplements $[4,5,7]$.

In conclusion, the findings of the present study showed that even though the serum levels of calcium, phosphate, MG, Fe and plasma level of PTH are within the normal reference range in a Black South African population, the significant differences observed in some of these measured parameters are reflective of the dietary history and antenatal supplementations which ultimately play a significant role in the occurrence of PE.

\section{Author Contribution}

D. A Ofusori: Principal investigator, data analysis, discussion of the write up

J. Moodley: Conceived and supervised the research idea, participated in the discussion of write up

R. Moodley: Participated in the biochemical conception and research in the laboratory
T Padayachi: Participated in the clinical discussion

T. Naicker: Supervised the research and also participated in the write up

\section{References}

1. Moodley J (2008) Maternal deaths due to hypertensive disorders in pregnancy. Best Pract Res Clin Obstet Gynaecol 22: 559-567. [Crossref]

2. Mol BWJ, Roberts CT, Thangaratinam S, Magee LA, de Groot CJM, et al. (2016) Preeclampsia. Lancet. [Crossref]

3. Garratt FN (2009) Pre-eclampsia: a challenge to public health teams world-wide to ensure that maternal diets contain adequate levels of folic acid, $n 3$ polyunsaturated fatty acid and vitamin D at conception. Public Health 123: 95-96. [Crossref]

4. Richards DGD, Lindow SW, Carrara H, Knight R, Haswell SG, et al. (2014) A comparison of maternal calcium and magnesium levels in pre-eclamptic and normotensive pregnancies: an observational case-control study. BJOG 121: 327-336. [Crossref]

5. Akinloye O, Oyewale OJ, Oguntibeju OO (2010) Evaluation of trace elements in pregnant women with pre-eclampsia. African Journal of Biotechnology 32: 5196-5202.

6. Kisters K, Barenbrock M, Louwen F, Hausberg M, Rahn KH, et al. (2000) Membrane, intracellular, and plasma magnesium and calcium concentrations in preeclampsia. $\mathrm{Am} \mathrm{J}$ Hypertens 13: 765-769. [Crossref]

7. Udipi S, Ghugre P, Gokhale C (2012) Iron, Oxidative Stress and Health, Oxidative Stress - Molecular Mechanisms and Biological Effects.

8. Tranquilli AI, Dekker G, Magee LA, Roberts J, Sibai BM, et al. (2014) The classification, diagnosis and management of the hypertension disorders of pregnancy. A revised statement from ISSHP. Pregnancy Hypertens 4: 97-104. [Crossref]

9. Kim J, Kim YJ, Lee R, Moon JH, Jo I (2012) Serum levels of zinc, calcium, and iron are associated with the risk of preeclampsia in pregnant women. Nutr Res 32: 764-769. [Crossref]

10. Von Dadelszen P, Firoz T, Donnay F, Gordon R, Hofmeyr GJ, et al. (2012) Preeclampsia in low and middle-income countries-health services lessons learned from the PREEMPT (PRE-Eclampsia-Eclampsia Monitoring, Prevention and Treatment) project. $J$ Obstet Gynaecol Can 34: 917-926. [Crossref]

11. Hofmeyr GJ, Belizán JM, von Dadelszen P, Calcium and Pre-eclampsia (CAP) Study Group (2014) Low-dose calcium supplementation for preventing pre-eclampsia: a systematic review and commentary. BJOG 121: 951-957. [Crossref]

12. Kris-Etherton PM, Zhao G, Binkoski AE, Coval SM, Etherton TD (2001) The effects of nuts on coronary heart disease risk. Nutr Rev 59: 103-111. [Crossref]

13. Jeanine L. Marnewick, Fanie Rautenbach, Irma Venter, Henry Neethling, Dee M Blackhurst, et al. (2011) Effects of rooibos (Aspalathus linearis) on oxidative stress and biochemical parameters in adults at risk for cardiovascular disease. $J$ Ethnopharmacol 133: 46-52. [Crossref]

14. Amellal-Chibane and Benamara (2011) Total contents of major minerals in the nature yogurt and in yogurts with the date powder of three dry varieties. Am J Food Nutr 2: $74-78$

15. Heaney RP (2002) Effects of caffeine on bone and the calcium economy. Food Chem Toxicol 40: 1263-1270. [Crossref]

16. Bolling BW, McKay DL, Blumberg JB (2010) The phytochemical composition and antioxidant actions of tree nuts. Asia Pac J Clin Nutr 19: 117-123. [Crossref]

17. Djousse L, Rudich T, Gaziano JM (2009) Nut consumption and risk of hypertension in US male physicians. Clin Nutr 28: 10-14. [Crossref]

Copyright: (C)2018 Ofusori DA. This is an open-access article distributed under the terms of the Creative Commons Attribution License, which permits unrestricted use, distribution, and reproduction in any medium, provided the original author and source are credited. 